\title{
Factors Influencing Patient Experience in Primary Healthcare Clinics within the eThekwini Municipality in KwaZulu-Natal
}

\author{
Hope Padayachee \\ https://orcid.org/0000-0002-0942-3267 \\ University of KwaZulu-Natal, \\ South Africa \\ padayachee.hope@gmail.com
}

\author{
Emmanuel Mutambara \\ https://orcid.org/0000-0002-8030-9061 \\ University of KwaZulu-Natal, \\ South Africa \\ mutambarae@ukzn.ac.za
}

\begin{abstract}
Patient experience is seen as a fundamental measure for healthcare evaluation, which fuels the debate regarding the most relevant factors influencing patient experience. Limited empirical knowledge exists concerning the factors that influence patient experience from the users' perspective in South Africa. This study addresses the research gap by determining the factors influencing patient experience among primary healthcare users in Waterloo, Grove-End and Stonebridge communities in the eThekwini Municipality of KwaZulu-Natal. The study is quantitative, descriptive and cross-sectional, and utilises a selfadministered questionnaire that was distributed among 280 primary healthcare users. They strongly agreed (> 90\%) that all the factors presented in the study are contributors to their patient experience. The factor analysis determined the relevance of the factors as perceived by the respondents. It was found that the doctor's role (0.970), clinic cleanliness (0.943), coordination and continuity of care (0.943), and waiting time (0.914) are the most significant influencers of patient experience. Education (0.898), nurses (0.882), medication (0.854) and the quality of care (0.853) serve as moderate influencers. Access (0.745), family/friend involvement (0.722) and the physical state of the infrastructure $(0.714)$ are mild influencers of patient experience. Patient-centred care (0.639), management effectiveness (0.637), communication (0.596) and information $(0.443)$ were non-influencers of patient experience. User experience is multifaceted and each factor represents a varying level of influence. It is recommended that a patient-experience framework should be developed that can be linked to improvement initiatives within South Africa in an effort to support quality improvement.
\end{abstract}

Keywords: patient experience; primary healthcare users; factors of patient experience

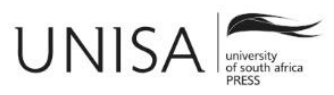

Africa Journal of Nursing and Midwifery https://upjournals.co.za/index.php/AJNM Volume $23 \mid$ Number $1|2021| \# 8110 \mid 17$ pages 


\section{Introduction}

The ultimate objective of healthcare evaluation is to inform decisions that improve service delivery (Moule et al. 2017). High-, middle- and low-income countries advocate the use of patient satisfaction as a reliable tool for healthcare evaluation (Al-Abri, and Al-Balushi 2014; Dunsch et al. 2018). However, Fenton et al. (2012) and Needham (2012) disagree, citing its use as myopic and sounding the call for patient experience tools in evaluation (Luxford and Sutton 2014).

Patient experience is defined as a reflection of the events that occur in the care process and therefore provides relevant information about the performance of the healthcare system and workers in order to meet the needs of the patient (Kieft et al. 2014; Price et al. 2014). Patient experience has received growing support from a body of researchers (Wolf 2015) amidst strong opposition from their counterparts (Manary et al. 2013). Despite the topical debate that surrounds patient experience, the provision of a highquality patient experience is now considered to be a key component of quality patient care (Siriwardena and Gillam 2014).

The Picker Principles of Patient-Centred Care include "respect for patients' values, preferences, and expressed needs," "information, communication, and education," "physical comfort," "emotional support and alleviation of fear and anxiety," "involvement of family and friends," "transition and continuity," "access to care," and "coordination and integration of care" when investigating the patient experience. The Institute for Patient- and Family-Centred Care includes "respect and dignity," "information sharing," and "participation and collaboration" in their analysis of patient experience (Ogden, Barr, and Greenfield 2017). The English National Health Service outlines these domains as critical to a "good" patient experience: "respect," "information and communication," "physical comfort," "emotional support," and "access to care" (Ahmed, Burt, and Roland 2014). The Institute of Medicine includes the following care factors: Safe, Timely, Efficient, Effective, Equitable and Patientcentred care, referred to as "STEEEP" (Shepherd, Cowie, and Beattie 2019). Based on the above, it is clear that there is significant overlap in terms of the factors that may influence patient experience. However, in South Africa (SA) there is limited research regarding which factors influence patient experience and which factors are the most relevant influencers of experience from the perspective of the patient (Becker et al. 2014). Therefore, the objective of this study is to determine which factors influence patient experience and the degree of influence. This study may prove beneficial for developing a comprehensive patient-experience framework that can be linked with improvement initiatives.

\section{Aim of the Study}

The aim of this study is to examine the factors that influence the experience of primary healthcare (PHC) users in the eThekwini Municipality of KwaZulu-Natal (KZN). 
Research Methods and Design

\section{Study Design}

A quantitative research approach was adopted using a descriptive research design. The survey research strategy was applied.

\section{Setting}

The study was set within three communities of Waterloo, Grove-End and Stonebridge located in the eThekwini Municipality of KZN.

\section{Study Population and Sampling Strategy}

There were 1500 houses in total within the $2 \mathrm{~km}$ radius of the three communities (Waterloo, Grove-End and Stonebridge) in eThekwini Municipality of KZN. This data was drawn from the eThekwini Housing Department in Unit 20, Phoenix. The total number of houses was determined through a map of the region and the sample of 300 was based on a sample size table with a confidence interval of $95 \%$ and a 5\% margin of error (Sekaran and Bougie 2016). The sample population of 300 (one PHC clinic user per household) was obtained (Waterloo [100], Grove-End [100] and Stonebridge [100]) using a cluster sampling strategy where the number of houses was similar in the $2 \mathrm{~km}$ radius of the three communities.

\section{Data Collection}

The author developed a data collection tool based on the Consumer Assessment of Healthcare Providers and Systems Tool, Primary Care Assessment Tool and Patient Experience Survey Tool (Wang et al. 2013). To ensure the validity of the survey instrument it was pre-tested with 30 respondents from the Waterloo, Grove-End and Stonebridge communities who were not included in the final 280 respondents. Field surveyors completed the patient experience survey over a period of four weeks from Monday to Friday (8am-6pm). The survey team comprised 10 individuals, including one field co-ordinator (researcher), one data entry person, one driver and seven surveyors (English and isiZulu) who served to ensure an efficient data collection process for both English-speaking and non-English-speaking respondents. Surveyors provided explanations for the questionnaire line items to ensure that the responses were valuable. A total of 300 questionnaires were collected, yielding a 100\% response rate; 20 questionnaires were excluded due to being incomplete; 280 questionnaires were included for the data analysis.

\section{Data Analysis}

The quantitative data were analysed through the Statistical Package for Social Sciences (SPSS) Version 25.0. A frequency analysis outlined the demographic profile of the participants and factors that influence patient experience. A principal component analysis determined the relevance of the factors as perceived by the users. 


\section{Ethical Consideration}

Approval was obtained from the Humanities and Social Sciences Research Ethics Committee with protocol reference: HSS/0126/017D. Ethical principles of informed consent, confidentiality and anonymity were maintained.

Results

Table 1: Demographic summary

\begin{tabular}{|c|c|c|c|}
\hline Variable & |Category & Frequency & $\%$ \\
\hline \multirow{3}{*}{ Age } & Up to 30 years & 102 & $36.40 \%$ \\
\hline & $31-45$ years & 133 & $47.50 \%$ \\
\hline & $46+$ years & 45 & $16.10 \%$ \\
\hline \multirow{2}{*}{ Gender } & Male & 94 & $33.57 \%$ \\
\hline & Female & 186 & $66.43 \%$ \\
\hline \multirow{2}{*}{ Race } & Black & 109 & $38.90 \%$ \\
\hline & Indian & 171 & $61.10 \%$ \\
\hline
\end{tabular}

Table 1 demonstrates the demographic profile of the respondents and reveals that the majority belong to the age group of 31-45 years, and two thirds are of the female gender. More than one third of respondents are younger than 31 years of age. As the age categories progress beyond 46 years, there is a decline in the number of respondents. The majority of respondents are of Indian ethnicity.

Table 2: Factors influencing the experience of primary healthcare users

\begin{tabular}{|c|c|c|c|c|c|c|c|}
\hline & & \multicolumn{6}{|c|}{ Frequency Distribution } \\
\hline & 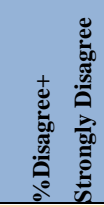 & 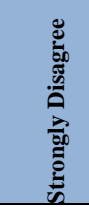 & 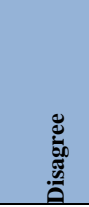 & 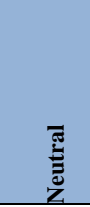 & 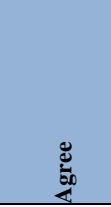 & 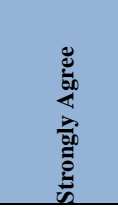 & 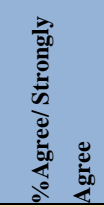 \\
\hline $\begin{array}{l}\text { 1. Access to the clinic influences } \\
\text { my patient experience }\end{array}$ & $0.4 \%$ & $0.4 \%$ & $0.0 \%$ & $4.6 \%$ & $15.7 \%$ & $79.3 \%$ & $95.0 \%$ \\
\hline $\begin{array}{l}\text { 2. The physical state of the } \\
\text { infrastructure influences my } \\
\text { patient experience }\end{array}$ & $1.4 \%$ & $1.4 \%$ & $0.0 \%$ & $2.5 \%$ & $16.4 \%$ & $79.6 \%$ & $96.0 \%$ \\
\hline $\begin{array}{l}\text { 3. Involving my family and } \\
\text { friends in my care influences my } \\
\text { patient experience }\end{array}$ & $1.1 \%$ & $1.1 \%$ & $0.0 \%$ & $4.6 \%$ & $15.7 \%$ & $78.6 \%$ & $94.3 \%$ \\
\hline
\end{tabular}




\begin{tabular}{|c|c|c|c|c|c|c|c|}
\hline $\begin{array}{l}\text { 4. Waiting time influences my } \\
\text { patient experience }\end{array}$ & $0.7 \%$ & $0.7 \%$ & $0.0 \%$ & $8.6 \%$ & $16.1 \%$ & $74.6 \%$ & $90.7 \%$ \\
\hline $\begin{array}{l}\text { 5. The quality of care influences } \\
\text { my patient experience }\end{array}$ & $0.4 \%$ & $0.4 \%$ & $0.0 \%$ & $7.5 \%$ & $15.7 \%$ & $76.4 \%$ & $92.1 \%$ \\
\hline $\begin{array}{l}\text { 6. Information influences my } \\
\text { patient experience }\end{array}$ & $0.0 \%$ & $0.0 \%$ & $0.0 \%$ & $2.1 \%$ & $15.7 \%$ & $82.1 \%$ & $97.8 \%$ \\
\hline $\begin{array}{l}\text { 7. Education influences my patient } \\
\text { experience }\end{array}$ & $0.7 \%$ & $0.7 \%$ & $0.0 \%$ & $3.9 \%$ & $15.4 \%$ & $80.0 \%$ & $95.4 \%$ \\
\hline $\begin{array}{l}\text { 8. The role of the doctor influences } \\
\text { my patient experience }\end{array}$ & $2.1 \%$ & $0.7 \%$ & $1.4 \%$ & $3.6 \%$ & $14.6 \%$ & $79.6 \%$ & $94.2 \%$ \\
\hline $\begin{array}{l}\text { 9. The effectiveness of } \\
\text { management in producing positive } \\
\text { outcomes influences my patient } \\
\text { experience }\end{array}$ & $3.2 \%$ & $1.1 \%$ & $2.1 \%$ & $6.1 \%$ & $13.9 \%$ & $76.8 \%$ & $90.7 \%$ \\
\hline $\begin{array}{l}\text { 10. The role of medication } \\
\text { influences my patient experience }\end{array}$ & $2.1 \%$ & $2.1 \%$ & $0.0 \%$ & $6.1 \%$ & $16.1 \%$ & $75.7 \%$ & $91.8 \%$ \\
\hline $\begin{array}{l}\text { 11. Communication influences my } \\
\text { patient experience }\end{array}$ & $0.4 \%$ & $0.4 \%$ & $0.0 \%$ & $7.1 \%$ & $15.4 \%$ & $77.1 \%$ & $92.5 \%$ \\
\hline $\begin{array}{l}\text { 12. Patient-centred care influences } \\
\text { my patient experience }\end{array}$ & $0.4 \%$ & $0.4 \%$ & $0.0 \%$ & $6.1 \%$ & $15.4 \%$ & $78.2 \%$ & $93.6 \%$ \\
\hline $\begin{array}{l}\text { 13. The role of the nurse influences } \\
\text { my patient experience }\end{array}$ & $1.8 \%$ & $1.8 \%$ & $0.0 \%$ & $6.4 \%$ & $13.9 \%$ & $77.9 \%$ & $91.8 \%$ \\
\hline $\begin{array}{l}\text { 14. Cleanliness in the clinic } \\
\text { influences my patient experience }\end{array}$ & $2.9 \%$ & $2.9 \%$ & $0.0 \%$ & $6.4 \%$ & $14.6 \%$ & $76.1 \%$ & $90.7 \%$ \\
\hline $\begin{array}{l}\text { 15.Coordination and continuity of } \\
\text { care influences my patient } \\
\text { experience }\end{array}$ & $2.9 \%$ & $2.9 \%$ & $0.0 \%$ & $6.1 \%$ & $14.6 \%$ & $76.4 \%$ & $91.0 \%$ \\
\hline Summary Variable & $1.36 \%$ & & & & & & $93.17 \%$ \\
\hline
\end{tabular}

The results in Table 2 outline factors influencing patient experience in primary healthcare facilities. The percentages reported in the "strongly disagree" and "disagree" columns were aggregated; the percentages reported in the "agree" and "strongly agree" responses were aggregated. The Cronbach's Alpha value of 0.936 reflects a high internal consistency. More than $90 \%$ of the respondents agree that the factors indicated in Table 2 influence patient experience. The respondents (97.8\%) indicated that information and the physical state of the infrastructure (96\%) influence patient experience. Respondents agreed on access to the clinic (95\%) and patient education (95.4\%) as influencers. Welcoming the involvement of family/ friends (94.3\%) and the role of the doctor $(94.2 \%)$ are important factors in patient experience. Patient-centred care $(93.6 \%)$ and communication $(92.5 \%)$ were found to influence patient experience. 
The quality of care (92.1\%), medication $(91.8 \%)$ and the role of the nurse $(91.8 \%)$ influence patient experience. Moreover, waiting time (90.7\%), coordination and continuity of care $(91.0 \%)$, and the effectiveness of management towards producing positive outcomes $(90.7 \%)$ influence the patient experience. Respondents $(90.7 \%)$ also agree that cleanliness in the clinic influences patient experience.

Table 3: Factor analysis of patient experience domains

\begin{tabular}{|c|c|c|c|}
\hline \multirow{2}{*}{$\begin{array}{l}\text { Domains of Patient Experience } \\
\text { (Conceptual Framework) }\end{array}$} & \multicolumn{3}{|c|}{ Principal Components (Latent Factors) } \\
\hline & Factor 1 & Factor 2 & Factor 3 \\
\hline Waiting Time & 0.914 & & \\
\hline Quality of Care & 0.853 & & \\
\hline Access & 0.745 & & \\
\hline Family Involvement & 0.722 & & \\
\hline State of Physical Infrastructure & 0.714 & & \\
\hline Communication & 0.596 & & \\
\hline Clinic Cleanliness & & 0.943 & \\
\hline Coordination/ Continuity of Care & & 0.943 & \\
\hline Nurse's Role & & 0.882 & \\
\hline Patient-Centred Care & & 0.639 & \\
\hline Doctor’s Role & & & 0.970 \\
\hline Education & & & 0.898 \\
\hline Medication's Role & & & 0.854 \\
\hline $\begin{array}{l}\text { Management's Positive } \\
\text { Outcomes }\end{array}$ & & & 0.637 \\
\hline Information & & & 0.443 \\
\hline Chronbach's Alpha & 0.911 & 0.931 & 0.870 \\
\hline Suggested sub-domain name & $\begin{array}{l}\text { Communication, } \\
\text { access and facility } \\
\text { sub-domain }\end{array}$ & $\begin{array}{l}\text { Nurse/Clinic } \\
\text { care sub- } \\
\text { domain }\end{array}$ & $\begin{array}{l}\text { Doctor's/management } \\
\text { sub-domain }\end{array}$ \\
\hline
\end{tabular}

It was found that the role of the doctor (0.970), clinic cleanliness, coordination and continuity of care (0.943), and waiting time (0.914) are the most significant influencers of patient experience.

\section{Discussion}

\section{Waiting Time}

Waiting time influenced the patient experience. The factor analysis indicates waiting time is a significant influencer of patient experience. Vadhana (2012), Amatya et al. (2017) and Mehata et al. (2017) showed waiting time to be a significant factor that 
influenced patient experience. Studies have demonstrated that long waiting times negatively impact patient experience (Dell et al. 2019; Ho 2014; Nottingham, Johnson and Russell 2018; Robinson et al. 2020; Xie and Or 2017).

\section{Quality of Care}

Quality of care influenced patient experience. The factor analysis revealed that quality of care is a moderate influencer of patient experience. Lupo $(2016,468)$ defines "the quality of care as the degree to which health services for individuals and populations increase the likelihood of desired health outcomes and are consistent with current professional knowledge." Quality healthcare is described as being able to meet the health needs of the patient at the lowest cost and according to the expected professional standards and regulations (Amatya et al. 2017). The most reliable method to improve patient experience comprises the provision of consistent, personalised, and reliable care for the patient, which is tantamount to quality of care (Nnebue et al. 2014).

\section{Access}

Access influenced patient experience. The factor analysis revealed that access is a mild influencer of patient experience. In SA, "access, has been constitutionally mandated as a basic human right" (Levesque, Harris, and Russell et al. 2013, 12) and influences the patient experience (Scheffler et al. 2015). A survey showed that difficulty in accessing care influences patient experience (Stremikis, Schoen, and Fryer 2011).

\section{Family/ Friend Involvement}

Family/friend involvement was found to influence patient experience. The factor analysis revealed that family/friend involvement is a mild influencer of patient experience. A contrasting viewpoint offered by Scanlon (2013) indicates that the involvement of family/friends has at times led to patients' personal information being divulged. However, welcoming family/friends in care processes could potentially provide effective support during clinical encounters in the case of vulnerable populations such as the elderly, children and pregnant women, thus influencing the patient experience positively (Bélanger, Desmartis, and Coulombe 2018).

\section{The State of the Physical Infrastructure}

The state of the physical infrastructure influenced patient experience. The factor analysis revealed that the state of the physical infrastructure is a mild influencer of patient experience. Ahmad et al. (2011) agree that the physical environment in a public health facility is a major determinant influencing patient experience. A report by the National Department of Health (NDoH) and the Health Systems Trust (DoH 2017, 20) "indicates that the physical state of the infrastructure in healthcare facilities in SA is poor." Young (2016) has attributed this to the unequal development and general lack of maintenance within primary healthcare facilities. The National Audit for Healthcare 
Facilities indicates that sub-standard infrastructure contributes to sub-standard delivery of care and negative patient experiences (NDoH 2012).

\section{Communication}

Communication influenced patient experience. However, the factor analysis showed that communication is not a significant influencer of patient experience. The results of the factor analysis may be attributed to the understanding that communication serves as a key aspect in the role of the doctor, the role of the nurse, the education of the patient, the role of medication and the involvement of family/friends. Therefore, its significance as an individual domain influencing patient experience is less weighty. According to the National Audit for Healthcare Facilities (NDoH 2012), "mechanisms to communicate consistently and systematically with patients and to share with communities the results and the progress of quality improvement initiatives are lacking." Effective communication between patients and caregivers is known to have improved the patient experience (Kourkouta and Papathanasiou 2014). Bearing in mind that most communication takes place through the medium of health professionals, the roles of the doctor and nurse are highlighted.

\section{The Role of the Doctor}

The role of the doctor influenced patient experience. The factor analysis showed that the role of the doctor is a significant influencer of patient experience. Patients need reassurance that their doctor has the required skill set to produce positive health outcomes (Lan and Yan 2017). The importance of practitioner-patient interaction and its influence on the experience of care has been highlighted (Odhayani and Khawaja 2014, 24). According to Galhotra et al. (2013), the doctor plays an important role in the patient's experience of care.

\section{Education}

The education of the patient influenced the patient's experience. The factor analysis showed that the patient's education is a moderate influencer of patient experience. When patients are educated about health conditions, processes that they will follow and the general management of their well-being, they are better positioned for producing positive outcomes and a positive experience (Jha, Frye, and Schlimgen 2017).

\section{The Role of Medication}

The role of medication influenced patient experience. The factor analysis showed that the role of medication is a moderate influencer of patient experience. In SA, officials found that only one third of the clinics that were inspected had sufficient medication (NDoH 2012). The unavailability of medicines is a significant barrier to patients gaining access to much needed essential medicines and has a negative effect on patient experience (Bateman 2013; Magadzire et al. 2014; Wagenaar et al. 2014). 


\section{The Effectiveness of Management in Producing Positive Outcomes}

Managers play an important role in patient experience. However, the factor analysis showed that effective management is not a significant influencer in patient experience. Managers bear a great burden in ensuring that the healthcare quality exceeds the patient's expectations (Frojd et al. 2011). Jha, Frye, and Schlimgen $(2017,39)$ highlight the need for managers and healthcare workers to prioritise patient experience in order to improve the effectiveness of healthcare, as reflected in the following statement: "when leaders and staff are not focused on the experience that the patients have, that trust is diminished, and the effectiveness of healthcare is substantially reduced." Moreover, Kaufman and McCaughan (2013, 53) "contend that leaders cannot be seen to turn a blind eye to poor practice, as this sets the pattern of behaviour for the whole team"; the entire healthcare approach is a team-driven approach and requires commitment from every team member. This statement is not meant to detract from the importance of the leader, as he/she is an important member of the health team. "Managers are essential participants in improving healthcare quality, and they need to participate in ensuring that patients receive safe, efficient and equal care" (Frojd et al. 2011, 228). Whilst the patients do agree that this is an important aspect of their experience, the latent factor analysis provides a contrasting finding to that of the respondents' perspective and to other authors in this field of study. This could be attributed to the fact that management is not solely responsible for the effective functioning of the clinic or positive outcomes for the patient.

\section{Information}

Being informed influenced patient experience. The factor analysis showed that information is not a significant influencer in patient experience. This finding contrasts with preceding results and the findings of other studies. "The Batho Pele Principles of Access and Information require information to be readily available to citizens in order to empower them and to address their needs" (Dookie and Singh 2012, 71). The findings of the study may be attributed to the fact that information is an important aspect of patient experience, but like communication, it does not exist in isolation.

\section{Clinic Cleanliness}

Cleanliness influenced patient experience. The factor analysis showed that clinic cleanliness is a significant influencer in patient experience. An under-utilisation of health facilities due to negative patient perceptions about cleanliness was noted in Nepal (Sheikh, George, and Gilson 2014). "South Africa is failing in terms of cleanliness," according to the Operation Phakisa Report (RSA 2015, 38). Dirty environments and unhygienic toilet facilities contribute to negative patient experiences (Dunjwa 2016; Nevhutalu 2016; Saini et al. 2013; South African Medical Association 2015). Most participants in a South African study felt that more members of the public would willingly access public facilities if improvements were made (Maseko and Harris 2018). 


\section{Coordination and Continuity of Care}

Coordination and continuity of care influenced patient experience. The factor analysis showed that coordination and continuity of care is a significant influencer of patient experience. White et al. $(2014,63)$ define care coordination as "the deliberate organization of patient care activities between two or more participants (including the patient) involved in a patient's care to facilitate the appropriate delivery of healthcare services." Interventions that support the continuity and coordination of care have the potential to improve the care experiences of patients who require chronic support, support health worker satisfaction, improve health outcomes and promote the performance of health systems (Ho 2014). According to Schang, Waibel and Thomson (2013) and Shaw, Rosen and Rumbold (2011), integrated care reflects a concern to improve patient experience and achieve greater efficiency and value from health delivery systems. Based on the findings of the National Audit in South Africa (NDoH 2012), 23\% of facilities do not have referral guidelines, which implies poor coordination and continuity of care, eliciting a negative experience.

\section{The Role of the Nurse}

The role of the nurse influenced patient experience. The factor analysis showed that the role of the nurse is a moderate influencer of patient experience. It is generally accepted that health workers should provide quality care, but South African public sector health workers are often described as "cruel" or "uncaring" (Maseko and Harris 2018, 24). Barron and Padarath (2017) highlighted the shortage of nurses in SA, which contributed to high workloads and poor-quality care, thus eliciting a negative patient experience. Similarly, Tana (2013) confirmed that the insufficiency and inadequacy of health workers contributed to physical and mental exhaustion in patients whilst skilled health workers support positive outcomes and patient experiences (Kieft et al. 2014; Wanjau, Muiruri, and Ayodo 2012).

\section{Patient-Centred Care}

Patient-centred care influenced patient experience. The factor analysis provided a contrasting finding - patient centred-care is not a significant influencer of patient experience. Luxford and Sutton $(2014,20)$ explain that there should be "nothing about me without me in health care," emphasising "the need to understand the current experience of patients as well as partner with patients to drive improvement in health care." The importance of communication in promoting patient engagement is highlighted (Manary et al. 2013).

\section{Strengths and Limitations}

The field researchers collected data in a flexible time frame to cater for employed and unemployed clinic patrons, which ensured that males or females who were at work during the day were able to participate in the study. The study was limited to the context of primary healthcare, and results may not translate to non-clinic settings. The study is 
limited in its generalisability as it was conducted in small communities within the eThekwini Municipality. However, the study design is adaptable and can be replicated in other provinces. As a consequence, the findings may not be fully representative of the aspects of patient experience in other provinces and this should be taken into consideration when interpreting the results.

\section{Implications or Recommendations}

The study findings suggest that the user experience is multifaceted and requires a consideration of the various factors influencing experience. In contrast to the standard experience survey that is currently utilised by the $\mathrm{NDoH}$ where only six factors are included (Access to Care, Medicines, Safety, Cleanliness, Waiting Time, Values and Attitudes), additional factors should be considered when evaluating patient experience to address quality issues within the health sector. This study further recommends that a patient-experience framework be developed in South Africa to support quality improvement.

\section{Conclusion}

Understanding patients' views on their healthcare experiences is essential for any service to be improved. Identifying those factors that influence patient experience will help healthcare professionals provide improved care. A comprehensive determination of factors that influence patient experience and their level of relevance to patient experience is key to developing quality improvement reforms within the public health sector in South Africa.

\section{Acknowledgements}

The authors declare that they have no financial or personal relationship(s) that may have inappropriately influenced the writing of this article.

\section{Author Contributions}

Hope Padayachee was enrolled in a doctoral programme at the University of KwaZuluNatal. Dr Emmanuel Mutambara was involved in the development of the article and coauthored the article with Hope Padayachee.

\section{Disclaimer}

The views expressed in the submitted article represent those of the author and do not represent the University of KwaZulu-Natal.

\section{Source(s) of Support}

No funding was obtained for the research. 


\section{References}

Ahmad, I., A. Nawaz, S. Khan, H. Khan, M. A. Rashid, and M. H. Khan. 2011. "Predictors of Patient Satisfaction." Gomal Journal of Medical Sciences 9: 183-88.

Ahmed, F., J. Burt, and M. Roland. 2014. "Measuring Patient Experience: Concepts and Methods.” Patient 7: 235-41. https://doi.org/10.1007/s40271-014-0060-5.

Al-Abri, R., and A. Al-Balushi. 2014. "Patient Satisfaction Survey as a Tool Towards Quality Improvement." Oman Medical Journal 29 (1): 3-7. https://doi.org/10.5001/omj.2014.02.

Amatya, B., S. Koirala, K. Schmidt, and L. Hung. 2017. “A Case Study on Measuring Patients' Perception of Quality of Health Service at Kirnetar Health Centre, Dhulikhel Hospital by a Patient Satisfaction Survey." International Research Journal of Public and Environmental Health 4 (10): 270-76. Accessed May 12, 2018. https://journalissues.org/irjpeh/wpcontent/uploads/sites/8/2017/11/Amatya-et-al.pdf.

Barron, P., and A. Padarath. 2017. "Twenty Years of the South African Health Review." In South African Health Review, edited by P. Barron and A. Padarath, 1-10. Durban: Health Systems Trust. Accessed January 12, 2020.

https://journals.co.za/docserver/fulltext/healthr_2017_a3.pdf?expires=1610457273\&id=id $\&$ accname $=$ guest $\&$ checksum $=0777 F 797 E 5$ A9F3A2B168DD9C212A5A79.

Bateman, C. 2013. "Drug Stock-Outs: Inept Supply-Chain Management and Corruption." South African Medical Journal 103 (9): 600-2. https://doi.org/10.7196/SAMJ.7332.

Becker, E. R., J. M. Hockenberry, J. Bae, A. C. Avgar, S. S. Liu, I. Wilson, and A. Milstein. 2014. "Factors in Patients' Experience of Hospital Care: Evidence from California, 2009-2011.” Patient Experience Journal 1 (1): 95-11. https://doi.org/10.35680/2372-0247.1014.

Bélanger, L., M. Desmartis, and M. Coulombe. 2018. "Barriers and Facilitators to Family Participation in the Care of Their Hospitalized Loved Ones." Patient Experience Journal 5 (1): a9. https://doi.org/10.35680/2372-0247.1250.

Dell, C. A., J. Stempien, L. Broberg, A. Husband, L. Jurke, B. Rohr, J. Smith, J. Rubin, S. Tupper, D. Goodridge, C. Fornssler, and L. Fele-Slaferek. 2019. "A Case Study of the Patient Wait Experience in an Emergency Department with Therapy Dogs.” Patient Experience Journal 6 (1): a14. https://doi.org/10.35680/2372-0247.1306.

DoH (Department of Health). 2017. Annual Report 2016/17. Pretoria: Department of Health. Accessed January 13, 2021.

https://www.gov.za/sites/default/files/gcis_document/201710/national-department-healthannual-report-2016-2017a.pdf.

Dookie, S., and S. Singh. 2012. "Primary Health Services at District Level in South Africa: A Critique of the Primary Health Care Approach." BMC Family Practice 13: a67. https://doi.org/10.1186/1471-2296-13-67. 
Dunjwa, M. 2016. "Public Health Facilities Audit Results: Office of Health Standards Compliance (OHSC) Briefing." Pretoria: Parliamentary Monitoring Group. Accessed January 12, 2021. https://pmg.org.za/committee-meeting/22233/.

Dunsch, F., D. K. Evans, M. Macis, and Q. Wang. 2018. "Bias in Patient Satisfaction Surveys: A Threat to Measuring Healthcare Quality.” BMJ Global Health 3: e000694. https://doi.org/10.1136/bmjgh-2017-000694.

Fenton, J. J., A. F. Jerant, K. D. Bertakis, and P. Franks. 2012. "The Cost of Satisfaction: A National Study of Patient Satisfaction, Health Care Utilization, Expenditures, and Mortality." Archives of Internal Medicine 172 (5): 405-11. https://doi.org/10.1001/archinternmed.2011.1662.

Frojd, C., C. L. Swenne, C. Rubertsson, L. Gunningberg, and B. Wadensten. 2011. 'Patient Information and Participation Still in Need of Improvement: Evaluation of Patients' Perceptions of Quality of Care.” Journal of Nursing Management 19: 226-36. https://doi.org/10.1111/j.1365-2834.2010.01197.x.

Galhotra, A., S. S. Sarpal, S. Gupta, and N. K. Goel. 2013. “A Cross Sectional Study on Patient Satisfaction toward Services Received at Rural Health Centre, Chandigarh, North India." Annals of Tropical Medicine and Public Health 6 (2): 240-44. https://doi.org/10.4103/1755-6783.116501.

Ho, E. T. L. 2014. "Improving Waiting Time and Operational Clinic Flow in a Tertiary Diabetes Center.” British Medical Journal of Quality Improvement 2: u201918.w1006. https://doi.org/10.1136/bmjquality.u201918.w1006.

Jha, D., A. K. Frye, and J. Schlimgen. 2017. "Evaluating Variables of Patient Experience and the Correlation with Design." Patient Experience Journal 4 (1): 37-45. https://doi.org/10.35680/2372-0247.1176.

Kaufman, G., and D. McCaughan. 2013. "The Effect of Organisational Culture on Patient Safety.” Nursing Standard 27 (43): 50-56. https://doi.org/10.7748/ns2013.06.27.43.50.e7280.

Kieft, R. A., B. B. de Brouwer, A. L. Francke, and D. M. Delnoij. 2014. "How Nurses and Their Work Environment Affect Patient Experiences of the Quality of Care: A Qualitative Study." BMC Health Services Research 14: a249. https://doi.org/10.1186/1472-6963-14249.

Kourkouta, L., and I. V. Papathanasiou. 2014. "Communication in Nursing Practice." Materia Socio-Medica 26 (1): 65-67. https://doi.org/10.5455/msm.2014.26.65-67.

Lan, Y.-L., and Y.-H. Yan. 2017. "The Impact of Trust, Interaction, and Empathy in DoctorPatient Relationship on Patient Satisfaction.” Journal of Nursing and Health Studies 2:2. https://doi.org/10.21767/2574-2825.100015. 
Levesque, J. F., M. F. Harris, and G. Russell. 2013. "Patient-Centred Access to Health Care: Conceptualising Access at the Interface of Health Systems and Populations." International Journal for Equity in Health 12 (1): a18. https://doi.org/10.1186/1475-9276-12-18.

Lupo, T. 2016. “A Fuzzy Framework to Evaluate Service Quality in the Healthcare Industry: An Empirical Case of Public Hospital Service Evaluation in Sicily." Applied Soft Computing 40: 468-75. https://doi.org/10.1016/j.asoc.2015.12.010.

Luxford, K., and S. Sutton. 2014. "How Does Patient Experience Fit into the Overall Health Picture?” Patient Experience Journal 1 (1): 20-27. Accessed January 12, 2021. https://pxjournal.org/cgi/viewcontent.cgi?article=1002\&context=journal.

Magadzire, B. P., A. Budden, K. Ward, R. Jeffery, and D. Sanders. 2014. "Frontline Health Workers as Brokers: Provider Perceptions, Experiences and Mitigating Strategies to Improve Access to Essential Medicines in South Africa.” BMC Health Services Research 14 (1): a520. https://doi.org/10.1186/s12913-014-0520-6.

Manary, M. P., W. Boulding, R. Staelin, and S. W. Glickman. 2013. "The Patient Experience and Health Outcomes." New England Journal of Medicine 368: 201-3. https://doi.org/10.1056/NEJMp1211775.

Maseko, L., and B. Harris. 2018. "People Centredness in Health System Reform: Public Perceptions of Private and Public Hospitals in South Africa." South African Journal of Occupational Therapy 48 (1): 22-27. https://doi.org/10.17159/2310-3833/2017/vol48n1a5.

Mehata, S., Y. R. Paudel, M. Dariang, K. K. Aryal, S. Paudel, R. Mehta, S. King, and S. Barnett. 2017. "Factors Determining Satisfaction among Facility-Based Maternity Clients in Nepal.” BMC Pregnancy and Childbirth 17 (1): a319. https://doi.org/10.1186/s12884017-1532-0.

Moule, P., J. Armoogum, E. Douglass, and J. Taylor. 2017. "Evaluation and Its Importance for Nursing Practice.” Nursing Standard 31 (35): 55-63. https://doi.org/10.7748/ns.2017.e10782.

NDoH (National Department of Health). 2012. National Health Care Facilities Baseline Audit. National Summary Report, compiled by R. Visser, R. Bhana and F. Monticelli. Pretoria: National Department of Health. Accessed January 12, 2021. https://www.hst.org.za/publications/HST\%20Publications/NHFA_webready_0.pdf.

Needham, B. R. 2012. "The Truth about Patient-Experience: What We Can Learn from Other Industries, and How Three Ps Can Improve Health Outcomes, Strengthen Brands, and Delight Customers.” Journal of Healthcare Management 57 (4): 255-63. https://doi.org/10.1097/00115514-201207000-00006.

Nevhutalu, H. K. 2016. "Patients' Rights in South Africa's Public Health System: MoralCritical Perspectives." PhD diss., University of Stellenbosch. 
Nnebue, C.C., U. E. Ebenebe, E. D. Adinma, C. A. Iyoke, C. N. Obionu, and A. L. Ilika. 2014. "Clients' Knowledge, Perception and Satisfaction with Quality of Maternal Health Care Services at the Primary Health Care Level in Nnewi, Nigeria." Nigerian Journal of Clinical Practice 17 (5): 595-605. https://doi.org/10.4103/1119-3077.141425.

Nottingham, Q. J., D. M. Johnson, and R. S. Russell. 2018. "The Effect of Waiting Time on Patient Perceptions of Care Quality." Quality Management Journal 25 (1): $32-$ 45. https://doi.org/10.1080/10686967.2018.1404368.

Odhayani, A. A., and R. A. Khawaja. 2014. "Patient's Satisfaction: Insight into Access to Service, Interpersonal Communication and Quality of Care Issues." Middle East Journal of Family Medicine 12: 24-30. https://doi.org/10.5742/MEWFM.2014.92558.

Ogden, K., J. Barr, and D. Greenfield. 2017. "Determining Requirements for Patient-Centred Care: A Participatory Concept Mapping Study.” BMC Health Services Research 17 (1): a780. https://doi.org/10.1186/s12913-017-2741-y.

Price, R. A., M. N. Elliot, A. M. Laslavsky, R. D. Hays, W. G. Lehrmann, L. Rybowski, S. Edgeman-Levitan, and P. D. Cleary. 2014. "Examining the Role of Patient Experience Surveys in Measuring Health Care Quality." Medical Care Research and Review 71 (5): 522-54. https://doi.org/10.1177/1077558714541480.

Robinson, J., M. Porter, Y. Montalvo, and C. J. Peden. 2020. "Losing the Wait: Improving Patient Cycle Time in Primary Care." British Medical Journal Open Quality 9: e000910. https://doi.org/10.1136/bmjoq-2019-000910.

RSA (Republic of South Africa). 2015. Operation Phakisa Ideal Clinic Realisation and Maintenance Final Lab Report. Accessed January 14, 2021. https://www.idealhealthfacility.org.za/docs/2016/phakisa/Operation\%20Phakisa\%20Ideal $\%$ 20Clinic\%20Realisaation\%20\&\%20Maintenance\%20Final\%20report\%20May\%202015. pdf.

Saini, N. K., S. Singh, G. Parasuraman, and O. P. Rajoura. 2013. "Comparative Assessment of Satisfaction among Outpatient Department Patients Visiting Secondary and Tertiary Level Government Hospitals of a District in Delhi." Indian Journal of Community Medicine 38: 114-17. https://doi.org/10.4103/0970-0218.112449.

Scanlon, C. 2013. "Psycho-Social Perspectives on Living and Working with Violence in Distressed and Traumatised (Dis-)Organisations." DPhil diss., University of the West of England. Accessed March 10, 2018. http://eprints.uwe.ac.uk/22161.

Schang, L., S. Waibel, and S. Thomson. 2013. Measuring Care Coordination: Health System and Patient Perspectives. Report prepared for the Main Association of Austrian Social Security Institutions. London: LSE Health. 
Scheffler, E., S. Visagie, and M. Schneider. 2015. "The Impact of Health Service Variables on Healthcare Access in a Low Resourced Urban Setting in the Western Cape, South Africa." African Journal of Primary Health Care and Family Medicine 7 (1). http://doi.org/10.4102/phcfm.v7i1.820.

Sekaran, U., and R. Bougie. 2016. Research Methods for Business: A Skill-Building Approach. 7th ed. Haddington: John Wiley \& Sons.

Shaw, S., R. Rosen, and B. Rumbold. 2011. What Is Integrated Care? An Overview of Integrated Care in the NHS. London: Nuffield Trust.

Sheikh, K., A. George, and L. Gilson. 2014. "People-Centred Science: Strengthening the Practice of Health Policy and Systems Research." Health Research Policy and Systems 12: a19. https://doi.org/10.1186/1478-4505-12-19.

Shepherd, A. J., J. Cowie, and M. Beattie. 2019. "An Exploration of How Domains of Quality of Care Relate to Overall Care Experience." International Journal of Health Care Quality Assurance 32 (5): 844-56. https://doi.org/10.1108/IJHCQA-07-2018-0183.

Siriwardena, A., and S. Gillam. 2014. "Patient Perspectives on Quality." Quality Primary Care 22: $11-15$.

South African Medical Association. 2015. Submission to Minister of Health, National Department of Health Comments, in Respect of White Paper for National Health Insurance for South Africa: Towards Universal Coverage. Pretoria: SAMA. Accessed December 15, 2015. https://www.mm3admin.co.za/documents/docmanager/f447b6073c8f-4eb7-8da4-11bca747079f/00105160.pdf.

Stremikis, K., C. Schoen, and A.-K. Fryer. 2011. A Call for Change: The 2011 Commonwealth Fund Survey of Public Views of the U.S. Healthcare System. Washington, DC: The Commonwealth Fund.

Tana, V. V. 2013. "Experiences of Chronic Patients about Long Waiting Time at a Community Health Care Centre in the Western Cape.” MCur diss., University of Stellenbosch. https://scholar.sun.ac.za/handle/10019.1/80332.

Vadhana, M. 2012. "Assessment of Patient Satisfaction in an Outpatient Department of an Autonomous Hospital in Phnom Penh, Cambodia." MSc diss, Ritsumeikan Asia Pacific University.

Wagenaar, B. H., S. Gimbel, R. Hoek, J. Pfeiffer, C. Michel, J. L. Manuel, F. Cuembelo, T. Quembo, P. Afonso, S. Gloyd, and K. Sherr. 2014. "Stock-Outs of Essential Health Products in Mozambique-Longitudinal Analyses from 2011 to 2013." Tropical Medicine and International Health 19 (7): 791-801. https://doi.org/10.1111/tmi.12314. 
Wang, H. H., S. Y. Wong, M. C. S. Wong, X. L. Wei, J. J. Wang, D. K.T. Li, J. L. Tang, G. Y. Gao, and S. M. Griffiths. 2013. "Patients' Experiences in Different Models of Community Health Centers in Southern China." Annals of Family Medicine 11 (6): 51726. https://doi.org/10.1370/afm.1545.

Wanjau, K. N., B. W. Muiruri, and E. Ayodo. 2012. "Factors Affecting Provision of Service Quality in the Public Health Sector: A Case of Kenyatta National Hospital." International Journal of Humanities and Social Science 2 (13): 114-25.

White, B., P. A. Carney, J. Flynn, M. Marino, and S. Fields. 2014. "Reducing Hospital Readmissions through Primary Care Practice Transformation." Journal of Family Practice 63 (2): 67-73.

Wolf, J. A. 2015. State of Patient Experience 2015: A Global Perspective on the Patient Experience Movement. Bedford, TX: Beryl Institute.

Young, M. 2016. "Private vs. Public Healthcare in South Africa." Honours diss., Western Michigan University.

Xie, Z., and C. Or. 2017. "Associations between Waiting Times, Service Times, and Patient Satisfaction in an Endocrinology Outpatient Department: A Time Study and Questionnaire Survey." Inquiry: The Journal of Health Care Organization, Provision and Financing 54. https://doi.org/10.1177/0046958017739527. 